\title{
Climate factors and gestational diabetes mellitus risk - a systematic review
}

\author{
Emma V. Preston ${ }^{1}$, Claudia Eberle ${ }^{2}$, Florence M. Brown ${ }^{3}$ and Tamarra James-Todd ${ }^{1,4^{*}}$ (D)
}

\begin{abstract}
Background: Current and projected increases in global temperatures and extreme climate events have led to heightened interest in the impact of climate factors (i.e. ambient temperature, season/seasonality, and humidity) on human health. There is growing evidence that climate factors may impact metabolic function, including insulin sensitivity. Gestational diabetes mellitus (GDM) is a common pregnancy complication, with an estimated global prevalence of up to 14\%. While lifestyle and genetic risk factors for GDM are well established, environmental factors may also contribute to GDM risk. Previous reviews have summarized the growing evidence of environmental risk factors for GDM including endocrine disrupting chemicals and ambient air pollution. However, studies of the effects of climate factors on GDM risk have not been systematically evaluated. Therefore, we conducted a systematic review to summarize and evaluate the current literature on the associations of climate factors with GDM risk.

Methods: We conducted systematic searches in PubMed and EMBASE databases for original research articles on associations of climate factors (i.e. ambient temperature, season/seasonality, and humidity) with GDM and/or related glycemic outcomes for all publication dates through September 20th, 2020.

Results: Our search identified 16 articles on the associations of ambient temperature and/or season with GDM and maternal glycemic outcomes during pregnancy, which were included in this review. Despite inconsistencies in exposure and outcome assessment, we found consistent evidence of a seasonal effect on GDM risk, with higher prevalence of GDM and higher pregnancy glucose levels in summer months. We found suggestive evidence of an association between higher ambient temperature and elevated glucose levels from GDM screening tests.
\end{abstract}

Conclusion: Climate factors may be associated with GDM risk. However, further research is needed to evaluate these associations and to elucidate the specific mechanisms involved.

Keywords: Climate, Season, Temperature, Gestational diabetes, Pregnancy

\section{Background}

Increased awareness of global climate change has led to heightened interest in the impact of climatic factors on human health [1]. Historically, much of the research on the human health effects of climate change focused on extreme temperature events and

\footnotetext{
* Correspondence: titodd@hsph.harvard.edu

'Department of Environmental Health, Harvard T.H. Chan School of Public Health, Building 1, Room 1411, 677 Huntington Ave, Boston, MA 02118, USA ${ }^{4}$ Department of Epidemiology, Harvard T.H. Chan School of Public Health, Boston, MA, USA

Full list of author information is available at the end of the article
}

infectious diseases [2-4]. However, there is growing evidence indicating that climate factors (i.e. season, ambient temperature, and humidity) may alter metabolic function, including insulin sensitivity $[1,5]$. The insulin resistant state of pregnancy may be particularly sensitive to climate factors, which could impact the body's metabolism, increasing gestational diabetes (GDM) risk. Thus, it is important to review the state of the literature on climate factors and GDM.

GDM, defined as glucose intolerance that is less than overt diabetes first occurring during pregnancy, is one of the most common pregnancy complications [6]. The

(c) The Author(s). 2020 Open Access This article is licensed under a Creative Commons Attribution 4.0 International License, which permits use, sharing, adaptation, distribution and reproduction in any medium or format, as long as you give appropriate credit to the original author(s) and the source, provide a link to the Creative Commons licence, and indicate if changes were made. The images or other third party material in this article are included in the article's Creative Commons licence, unless indicated otherwise in a credit line to the material. If material is not included in the article's Creative Commons licence and your intended use is not permitted by statutory regulation or exceeds the permitted use, you will need to obtain permission directly from the copyright holder. To view a copy of this licence, visit http://creativecommons.org/licenses/by/4.0/. The Creative Commons Public Domain Dedication waiver (http://creativecommons.org/publicdomain/zero/1.0/) applies to the data made available in this article, unless otherwise stated in a credit line to the data. 
prevalence of GDM has increased over the past 20 years and is currently estimated to affect up to $14 \%$ of pregnancies worldwide [7], though estimates vary based on the population and diagnostic criteria [6, 8-10]. GDM is associated with both short- and long-term adverse pregnancy, maternal and neonatal outcomes, including preeclampsia, cesarean section, preterm birth, macrosomia and neonatal hypoglycemia $[7,11]$. Mothers are at increased risk of developing type 2 diabetes [12-14] and cardiovascular disease $[15,16]$ in later life. Recent studies demonstrate that offspring may be at increased risk of higher adiposity and abnormal glucose metabolism in mid-childhood $[6,11,17]$.

Lifestyle and genetic factors such as diet, body mass index (BMI), physical activity, parity, age, and family history may not fully account for GDM risk [18-20]. Recent reviews have examined the potential role of environmental exposures including endocrine disrupting chemicals [21, 22], toxic metals [21], and air pollution $[23,24]$ in the development of GDM. However, climate factors may also play a role in GDM risk [25-27]. With the current and projected rise in global surface temperatures and increased frequency of extreme weather events [28], we aim to review the role of climate factors on this significant pregnancy complication.

\section{Rationale for climate factors as a risk factor for gestational diabetes}

Previous meta-analyses and primary research studies have found associations between ambient temperature, season, and humidity with type 1 and/or type 2 diabetes [29-31]. Potential physiologic explanations for these associations include several different mechanisms, which have also been discussed as possible mechanisms for associations between climate factors and GDM. Cold ambient temperature may cause activation of brown adipose tissue leading to improved insulin sensitivity [32]. On the other hand, high ambient temperatures and relative humidity could cause dehydration and result in hemoconcentration during the summer, leading to spurious increased blood glucose concentrations [33]. Seasonal fluctuations in serum vitamin D levels could also contribute to the observed association between season and type 2 diabetes risk [34]. In fact, vitamin D may aid in glucose regulation by increasing insulin secretion and sensitivity, aiding in beta-cell function, and decreasing systemic inflammation [35]. Alternatively, changes in diet and physical activity levels related to ambient temperature, season, and humidity may contribute to observed seasonal fluctuations in diabetes risk.

A growing number of studies have evaluated climate factors as they relate to GDM; however, these studies have not been systematically reviewed. Therefore, we conducted a systematic review of epidemiological studies evaluating the associations of climate factors with GDM and glycemic outcomes during pregnancy, to assess how climate factors were associated with the continuum of glucose intolerance. We evaluated epidemiological studies identified in PubMed and EMBASE, summarized the state of the literature, identified research gaps, and suggested key next steps for future studies of the influence of climate factors on GDM. To our knowledge, this is the first systematic review of climate factors as they relate to GDM.

\section{Methods}

\section{Search strategy}

We conducted a systematic literature search in PubMed and EMBASE databases for original research articles for all publication dates through September 20th, 2020, based on the guidelines of the PRISMA statement [36]. We considered original epidemiologic studies in pregnant women written in the English language with available full-text. Studies were included in the review if they related one or more climate factors to one or more glucose-related outcomes during pregnancy. Maternal glycemic outcomes included gestational glucose levels, markers of insulin sensitivity, beta cell function, categories of glucose tolerance derived from glucose challenge test (GCT) and/or oral glucose challenge test (OGTT) screenings (e.g. abnormal GCT or OGTT values), or GDM diagnosis.

In PubMed we searched using the following combination of Medical Subject Headings (MeSH) terms and freetext title or abstract terms (tiab): ((diabetes, gestational $[\mathrm{MeSH}]$ OR gestational diabetes [tiab]) OR ((Diabetes Mellitus [Mesh:NoExp] OR glucose tolerance test [MeSH] OR blood glucose [MeSH] OR hyperglycemia [MeSH] OR diabetes [tiab] OR diabetic [tiab] OR blood glucose [tiab] OR glucose intolerance [tiab] OR glucose tolerance [tiab] OR hyperglycemia [tiab]) AND (Pregnancy [Mesh:NoExp] OR Pregnancy Outcome [Mesh: NoExp] OR Pregnancy, High-Risk [Mesh] OR Pregnancy Complications [Mesh:NoExp] OR pregnanc"[tiab] OR pregnant [tiab]))) AND (climate [MeSH] OR weather [MeSH] OR climate [tiab] OR seasonality [tiab] OR season [tiab] OR ambient temperature [tiab] or dew point [tiab] OR humidity [tiab]). We restricted our PubMEd search using the following search terms: NOT (Animals $[\mathrm{MeSH}]$ NOT Humans [MeSH]) NOT (Case Reports [ptyp] OR Comment [sb] OR Editorial [ptyp] OR Guideline [ptyp] OR Letter [ptyp] OR News [ptyp] OR Practice Guideline [ptyp]). In EMBASE, we searched using the following combination of Emtree and text search terms: ('pregnancy diabetes mellitus'/exp. OR 'gestational diabetes':ti,ab,kw) OR ((diabetes:ti,ab,kw OR 'glucose tolerance':ti,ab,kw OR 'glucose intolerance':ti,ab,kw OR hyperglycemia:ti,ab,kw OR 'blood glucose':ti,ab,kw OR 
'diabetes mellitus'/de OR 'impaired glucose tolerance'/de OR 'hyperglycemia'/de) AND ('pregnant woman'/exp. OR 'pregnancy'/exp. OR pregnancy:ti,ab,kw OR 'pregnant women':ti,ab,kw)) AND ('seasonal variation':ti,ab,kw OR season:ti,ab,kw OR 'ambient temperature':ti,ab,kw OR 'environmental temperature':ti,ab,kw OR weather:ti, ab,kw OR climate:ti,ab,kw OR 'climate change':ti,ab,kw OR 'climate'/exp. OR 'meteorological phenomena'/exp. OR 'environmental temperature'/exp. OR 'seasonal variation'/exp). In EMBASE, we used the following search restrictions: AND ([article]/lim OR [article in press]/lim) AND [humans]/lim AND [english]/lim.

Articles were excluded if they were not available in English, were duplicates, conducted in animals, had irrelevant exposures, or irrelevant outcomes, were irrelevant study types (i.e. case-reports, reviews, metaanalyses), were not in pregnant women, or the study outcomes occurred outside of pregnancy (e.g. postpartum glucose levels) (see Fig. 1). In addition to our database searches, we manually checked the listed references of identified articles and relevant reviews for additional articles that we may have missed in our search in order to maximize the likelihood of identifying all relevant articles.

\section{Results}

Our systematic search strategy returned 847 articles, 229 from PubMed and 618 from EMBASE (Fig. 1). We identified one additional article by reviewing article reference lists. After excluding duplicate articles $(n=83)$, we excluded an additional 734 articles through title and abstract screening. We included 31 articles in our full text review, and excluded an additional 15 based on our inclusion/exclusion criteria (non-pregnant population: $n=$

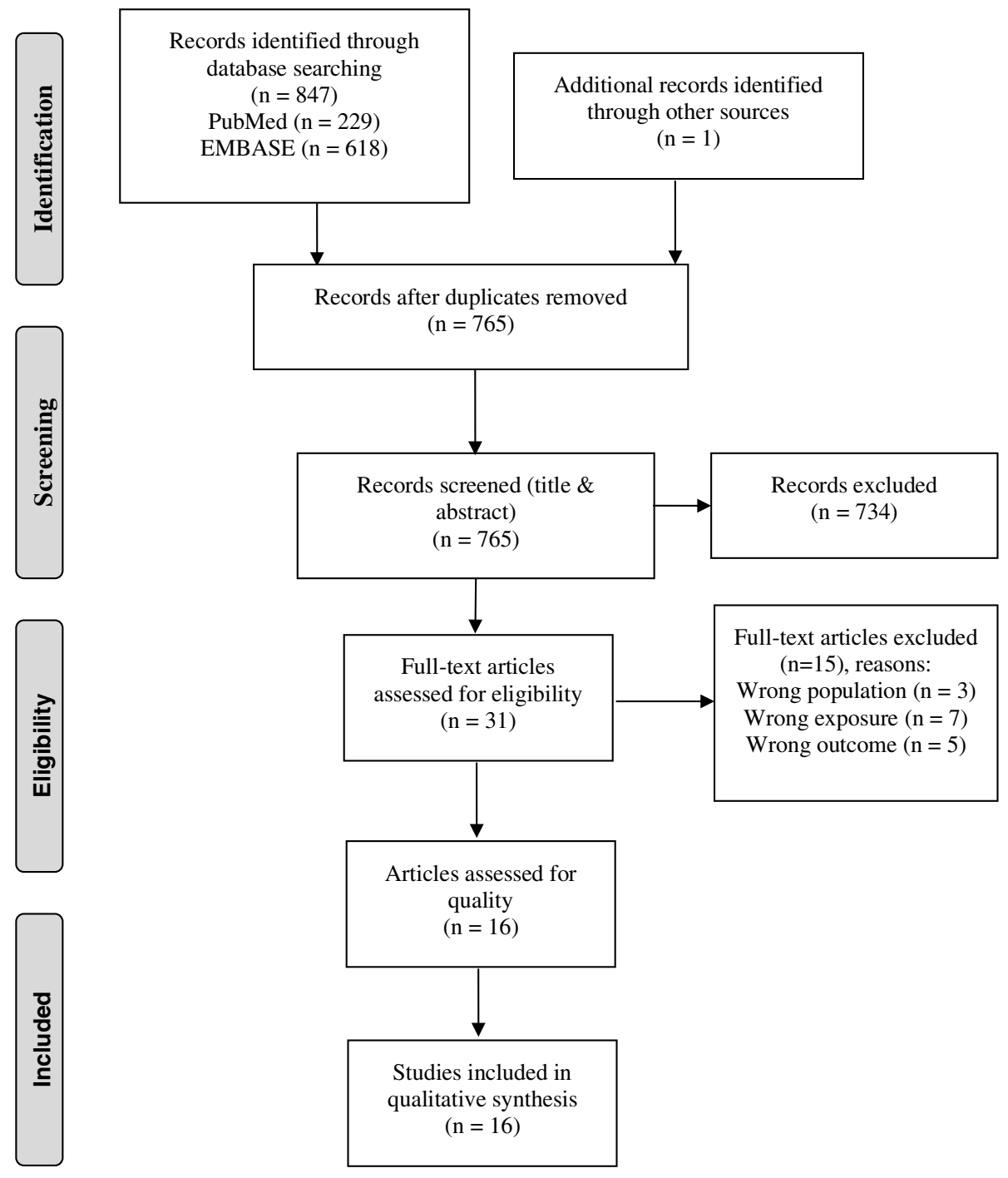

Fig. 1 PRISMA flow diagram illustrating the selection process for studies included in this review [adapted from Moher et al. 2009 [36]] 
3, wrong exposure: $n=7$, wrong outcome: $n=5$ ). We did not find any articles on humidity and GDM or maternal glycemic outcomes. Additionally, our search did not identify any articles that investigated other maternal or neonatal short and long-term health outcomes as consequences of GDM and/or glycemic outcomes during pregnancy associated with climate factors. In total, we included 16 articles on the associations of ambient temperature and/or season with GDM (Table 2) and maternal glycemic outcomes (Table 3) during pregnancy in this review.

\section{Glucose related study outcomes}

There was significant heterogeneity in method of GDM screening/diagnosis across the included studies. Table 1 summarizes the GDM screening methods and diagnostic criteria used by the included studies. The majority of screening methods fall into two categories: (1) a one-step approach, where GDM is diagnosed based on results of a single fasting oral glucose tolerance test (OGTT), or (2) a two-step approach, where women are pre-screened, generally with a non-fasting glucose challenge test (GCT), and only women with abnormal GCT glucose levels (e.g. $>140 \mathrm{mg} / \mathrm{dL}$ ) receive a subsequent OGTT to diagnose GDM. The International Association of Diabetes in Pregnancy Study Group (IADPSG) criteria follows a one-step approach using a fasting 2-h 75-g OGTT with relatively low glucose level thresholds, requiring only one abnormal value for a positive test. Many countries and organizations, including the WHO, have adopted the IADPSG criteria. Conversely, in the United States, GDM is generally screened and diagnosed using a more conservative twostep approach, consisting of [1] a non-fasting 50-g GCT, followed by [2] a fasting 3-h 100-g OGTT, with higher glucose level thresholds than the IADPSG criteria, requiring two abnormal values for a positive test [8]. Differences in GDM screening and diagnostic criteria are important factors to consider when comparing study results below.

Table 1 Gestational diabetes mellitus screening and diagnostic criteria

\begin{tabular}{|c|c|c|c|c|c|c|c|c|c|c|}
\hline \multirow[t]{2}{*}{ Guidelines } & \multirow[t]{2}{*}{ Year } & \multirow[t]{2}{*}{ Approach } & \multirow[t]{2}{*}{ GCT } & \multirow{2}{*}{$\begin{array}{l}\text { GCT } \\
\text { Glucose } \\
\text { Threshold }\end{array}$} & \multirow[t]{2}{*}{ OGTT } & \multicolumn{4}{|c|}{ OGTT Glucose Threshold Values } & \multirow{2}{*}{$\begin{array}{l}\text { GDM } \\
\text { Diagnosis }\end{array}$} \\
\hline & & & & & & Fasting & 1-h & 2-h & 3-h & \\
\hline \multicolumn{11}{|l|}{ One-step approaches } \\
\hline $\begin{array}{l}\text { International } \\
\text { Association of } \\
\text { Diabetes and } \\
\text { Pregnancy Study } \\
\text { Group (IADPSG) [48] }\end{array}$ & 2010 & 1-step & - & - & $75-g$ & $\begin{array}{l}5.1 \mathrm{mmol} / \mathrm{L}(92 \mathrm{mg} / \\
\mathrm{dL})\end{array}$ & $\begin{array}{l}10 \\
\text { mmol/ } \\
\text { L (180 } \\
\text { mg/dL) }\end{array}$ & $\begin{array}{l}8.5 \mathrm{mmol} / \mathrm{L}(153 \mathrm{mg} / \\
\mathrm{dL})\end{array}$ & - & $\begin{array}{l}\geq 1 \\
\text { abnormal } \\
\text { OGTT }\end{array}$ \\
\hline $\begin{array}{l}\text { World Health } \\
\text { Organization (WHO) } \\
{[49]}\end{array}$ & 1999 & 1-step & - & - & $75-9$ & $\begin{array}{l}7 \mathrm{mmol} / \mathrm{L}(126 \mathrm{mg} / \\
\mathrm{dL})\end{array}$ & - & $\begin{array}{l}7.8 \mathrm{mmol} / \mathrm{L}(140 \mathrm{mg} / \\
\mathrm{dL})\end{array}$ & - & $\begin{array}{l}\geq 1 \\
\text { abnormal } \\
\text { OGTT }\end{array}$ \\
\hline $\begin{array}{l}\text { WHO - Modified [45, } \\
50]\end{array}$ & 2006 & 1-step & - & - & $75-9$ & $\begin{array}{l}\text { DIP: } 7 \text { mmol/L (126 } \\
\mathrm{mg} / \mathrm{dL}) ; \mathrm{GDM}: 5.1- \\
6.9 \mathrm{mmol} / \mathrm{L}(92- \\
124 \mathrm{mg} / \mathrm{dL})\end{array}$ & & $\begin{array}{l}\text { DIP: } 11.1 \mathrm{mmol} / \mathrm{L} \\
(200 \mathrm{mg} / \mathrm{dL}) ; \mathrm{GDM}: \\
8.5-11 \mathrm{mmol} / \mathrm{L} \\
(153-198 \mathrm{mg} / \mathrm{dL})\end{array}$ & & $\begin{array}{l}\text { DIP or } \\
\text { GDM: } \geq 1 \\
\text { abnormal } \\
\text { OGTT }\end{array}$ \\
\hline \multicolumn{11}{|l|}{ Two-step approaches } \\
\hline $\begin{array}{l}\text { Australian Diabetes in } \\
\text { Pregnancy Society } \\
\text { (ADIPS) [51] }\end{array}$ & 1991 & 2-step & $50-9$ & $\begin{array}{l}7.8 \mathrm{mmol} / \\
\mathrm{L}(140 \\
\mathrm{mg} / \mathrm{dL})\end{array}$ & $75-9$ & $\begin{array}{l}5.5 \mathrm{mmol} / \mathrm{L}(99 \mathrm{mg} / \\
\mathrm{dL})\end{array}$ & - & $\begin{array}{l}8 \mathrm{mmol} / \mathrm{L}(144 \mathrm{mg} / \\
\mathrm{dL})\end{array}$ & - & $\begin{array}{l}\geq 1 \\
\text { abnormal } \\
\text { OGTT }\end{array}$ \\
\hline $\begin{array}{l}\text { Carpenter and } \\
\text { Coustan [52] }\end{array}$ & 1982 & 2-step & $50-\mathrm{g}$ & $\begin{array}{l}7.8 \mathrm{mmol} / \\
\mathrm{L}(140 \\
\mathrm{mg} / \mathrm{dL})\end{array}$ & $100-g$ & $\begin{array}{l}5.3 \mathrm{mmol} / \mathrm{L}(95 \mathrm{mg} / \\
\mathrm{dL})\end{array}$ & $\begin{array}{l}10 \\
\mathrm{mmol} / \\
\mathrm{L}(180 \\
\mathrm{mg} / \mathrm{dL})\end{array}$ & $\begin{array}{l}8.6 \mathrm{mmol} / \mathrm{L}(155 \mathrm{mg} / \\
\mathrm{dL})\end{array}$ & $\begin{array}{l}7.8 \\
\mathrm{mmol} / \\
\mathrm{L}(140 \\
\mathrm{mg} / \\
\mathrm{dL})\end{array}$ & $\begin{array}{l}\geq 2 \\
\text { abnormal } \\
\text { OGTT }\end{array}$ \\
\hline $\begin{array}{l}\text { National Diabetes } \\
\text { Data Group (NDDG) } \\
\text { Criteria [53] }\end{array}$ & 1979 & 2-step & $50-g$ & $\begin{array}{l}7.8 \mathrm{mmol} / \\
\mathrm{L}(140 \\
\mathrm{mg} / \mathrm{dL})\end{array}$ & $100-g$ & $\begin{array}{l}5.8 \mathrm{mmol} / \mathrm{L}(105 \\
\mathrm{mg} / \mathrm{dL})\end{array}$ & $\begin{array}{l}10.5 \\
\mathrm{mmol} / \\
\mathrm{L}(189 \\
\mathrm{mg} / \mathrm{dL})\end{array}$ & $\begin{array}{l}9.2 \mathrm{mmol} / \mathrm{L}(166 \mathrm{mg} / \\
\mathrm{dL})\end{array}$ & $\begin{array}{l}8.0 \\
\mathrm{mmol} / \\
\mathrm{L}(144 \\
\mathrm{mg} / \\
\mathrm{dL})\end{array}$ & $\begin{array}{l}\geq 2 \\
\text { abnormal } \\
\text { OGTT }\end{array}$ \\
\hline $\begin{array}{l}\text { WHO - Modified [46, } \\
49]\end{array}$ & 1999 & 2-step & $\begin{array}{l}\text { Random } \\
\text { glucose }\end{array}$ & $\begin{array}{l}6.5 \mathrm{mmol} / \\
\mathrm{L}(117 \\
\mathrm{mg} / \mathrm{dL})\end{array}$ & $75-g$ & $\begin{array}{l}6 \text { mmol/ (108 mg/ } \\
\mathrm{dL} \text { ) }\end{array}$ & - & $\begin{array}{l}7.8 \mathrm{mmol} / \mathrm{L}(140 \mathrm{mg} / \\
\mathrm{dL})\end{array}$ & - & $\begin{array}{l}\geq 1 \\
\text { abnormal } \\
\text { OGTT }\end{array}$ \\
\hline WHO - Modified [37] & 1999 & 2-step & $50-g$ & $\begin{array}{l}7.7 \mathrm{mmol} / \\
\mathrm{L}(139 \\
\mathrm{mg} / \mathrm{dL})\end{array}$ & $75-9$ & $6.1 \mathrm{mmol} / \mathrm{L}$ & - & $7.8 \mathrm{mmol} / \mathrm{L}$ & - & $\begin{array}{l}\geq 1 \\
\text { abnormal } \\
\text { OGTT }\end{array}$ \\
\hline
\end{tabular}


In addition to GDM diagnosis, we included studies with maternal glycemic outcomes such as additional categories of glucose intolerance based on GCT and/or OGTT screening results [e.g. abnormal GCT (>140 mg/ $\mathrm{dL}$ ), or hyperglycemia in pregnancy]. As with GDM, the definitions and thresholds used in these classifications varied across studies. Multiple studies assessed glucose levels, analyzed as continuous outcomes, usually from GCT and/or OGTT screenings. Two studies also assessed various markers of insulin resistance (IR) [e.g. Matsuda index and homeostasis model assessment of insulin (HOMA-IR, HOMA S)] and beta cell function [e.g. insulin sensitivity index 2 (ISSI-2), insulinogenic index (IGI)/HOMA-IR, and HOMA B].

Timing of outcome assessment also varied by study (Tables 2 \& 3), with GDM screening and glycemic outcome measurement typically occurring between 24 and 28 weeks gestation, but as early as $16-18$ weeks in some studies [42]. Differences in outcome assessment could also impact observed associations with climate factors as well as variability across studies.

\section{Climate factors \& GDM}

Seasonality of GDM Twelve studies evaluated associations between season and GDM (Table 2) [25-27, 3740, 42, 44-46, 54]. Despite differences in geographical location and seasonal definitions, the majority of studies consistently reported higher incidence or prevalence of GDM diagnosis in the summer and lower incidence or prevalence of GDM diagnosis in the winter [21, 25, 27, $37,38,42,45]$, while only three studies, two Australian studies $(n=2749$ [26]; $n=2120$ [40]) and one in the United Kingdom ( $n=1074$ [39]) reported no association between season of screening and GDM. A populationbased study of 4852 pregnancies located in Plymouth, $\mathrm{UK}$, reported higher prevalence of GDM in the spring $(2.3,95 \%$ CI: $1.5,3.2)$ rather than the summer but consistently lower GDM prevalence in the winter (1.4, 95\% CI: $0.8,2.3)$ compared to other seasons, although the differences were not statistically significant [46]. In a large South Australian study $(n=60,306)$, incidence of GDM was significantly associated with season of estimated date of conception, where adjusted incidence of GDM was highest in pregnancies with estimated conception dates in August (6.6\%) (Australian winter), with women entering second trimester-the time period of increasing insulin resistance-during the months of increasing temperature [44]. The lowest prevalence of GDM was among pregnancies with estimated conception dates in January (5.4\%) (Australian summer) [44], with women entering second trimester during the months of decreasing temperatures.
Seasonality of glycemic outcomes As with GDM, seasonal variations in gestational glucose levels have been reported as early as 1995 [26]. Eleven studies assessed the relationship between seasonality and maternal glycemic outcomes (Table 3) [25-27, 33, 37-40, 42, 45, 46]. Associations of season with blood glucose levels have been somewhat less consistent across studies compared to those with GDM, but studies have generally reported higher glucose levels in the summer. Two UK-based studies, one population-based study in Plymouth, UK $(n=4852)$ and one smaller cohort in Cambridge, UK $(n=1074)$ reported no associations of month or season of screening with glucose levels from fasting $2-\mathrm{h} 75-\mathrm{g}$ OGTTs $[39,46]$. A much larger Israeli retrospective cohort study $(n=59,882)$ also reported no associations of season of screening with glucose levels from a fasting 3h 100-g OGTT [33]. However, the authors did observe lower glucose levels from a non-fasting 50-g GCT in winter and higher GCT glucose levels in summer, as well as significantly higher odds of elevated GCT glucose levels (>140 mg/dL) in summer compared to winter (OR 1.58, 95\% CI: 1.51, 1.66) [33]. Five studies in Italy (5473) [42], Greece $(n=7618)$ [27], Spain $(n=2366)$ [38], and two in Australia $(n=7343,[45] ; n=2120$, [40]), observed higher $1 \mathrm{~h}$ and $2 \mathrm{~h}$ glucose levels from 2-h 75-g (3-h $100-\mathrm{g},[27,38])$ OGTTs in the summer and/or lower levels in the winter (autumn, [38]) compared to other seasons. Two studies in Sweden $(n=11,538)$ [25] and Australia $(n=2749)$ [26] reported higher $2 \mathrm{~h}$ glucose levels from a 75-g OGTT in the summer, but did not see differences in $1 \mathrm{~h}$ glucose levels by season $[25,26]$. However, the majority of these studies did not find variations in fasting glucose by season, except for a cohort in Australia that reported lower fasting glucose levels in summer compared to winter [40], which may reflect different regulation or sensitivity compared to postprandial glucose levels.

Ambient temperature \& GDM Eight studies evaluated the association between ambient temperature at varying time points during pregnancy and GDM (Table 2) [21, 25-27, 37, 38, 41, 43]. Three studies found no association between various measures of ambient temperature and GDM [25-27]. An older Australian study $(n=2749)$ [26] and a larger Swedish cohort study $(n=11,538)$ [25], reported no association between mean monthly temperature during the month of glucose screening and GDM, and a small Greek study $(n=768)$ reported no association between daily temperature at time of glucose screening and GDM [27]. The remaining five studies reported associations of various ambient temperature variables with increased odds or risk of GDM [21, 37, 38, 41, 43]. 


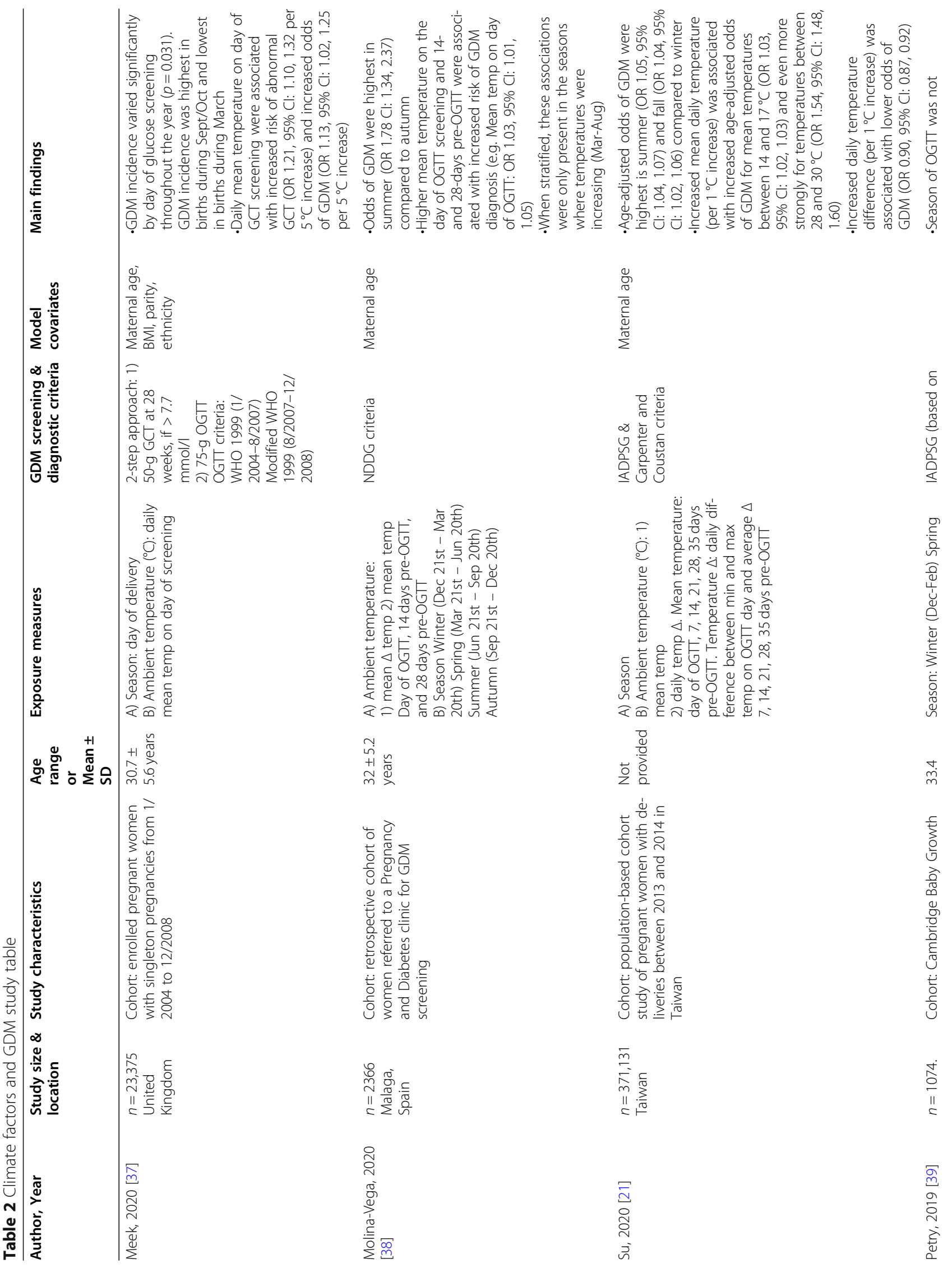




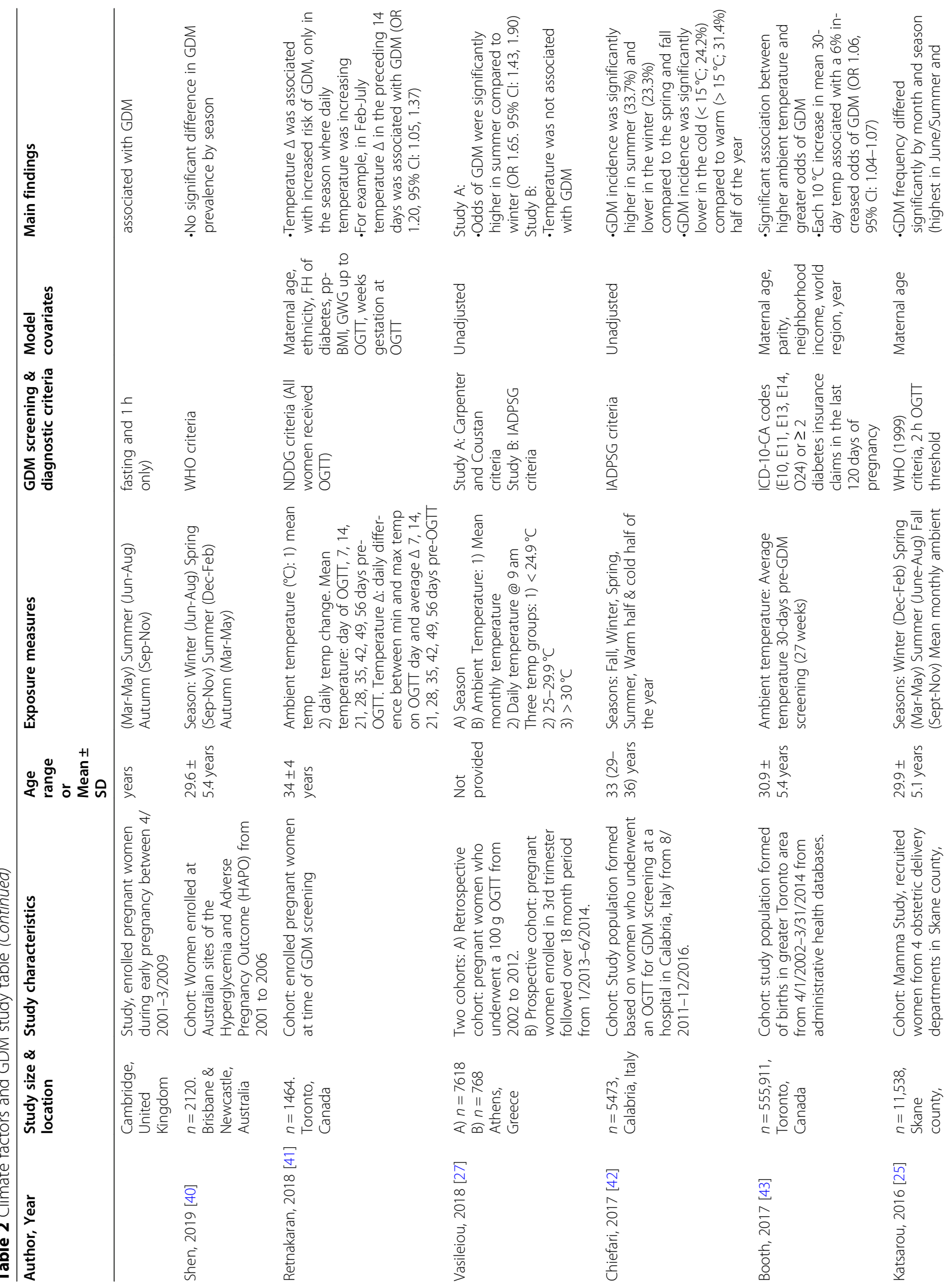




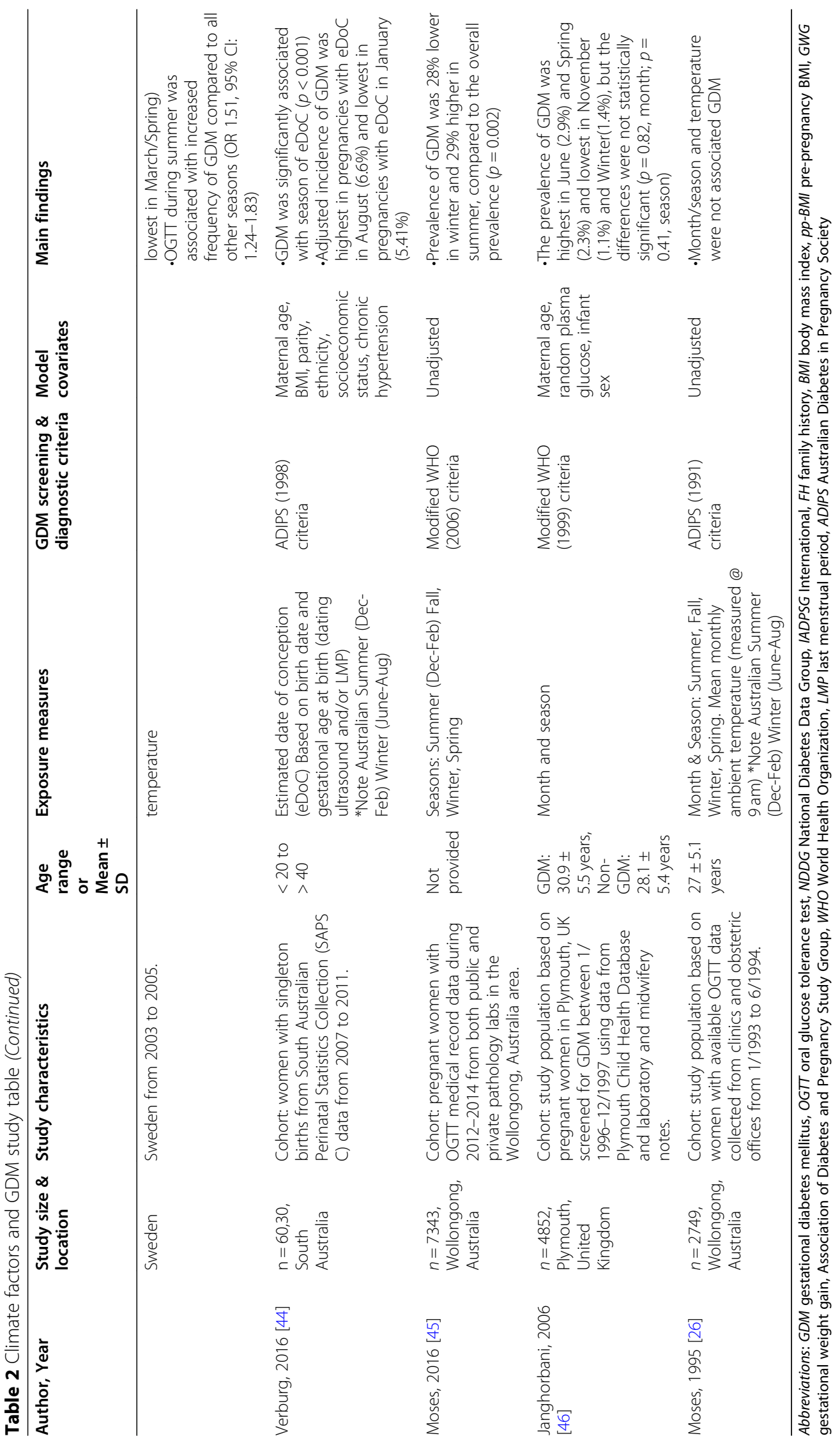




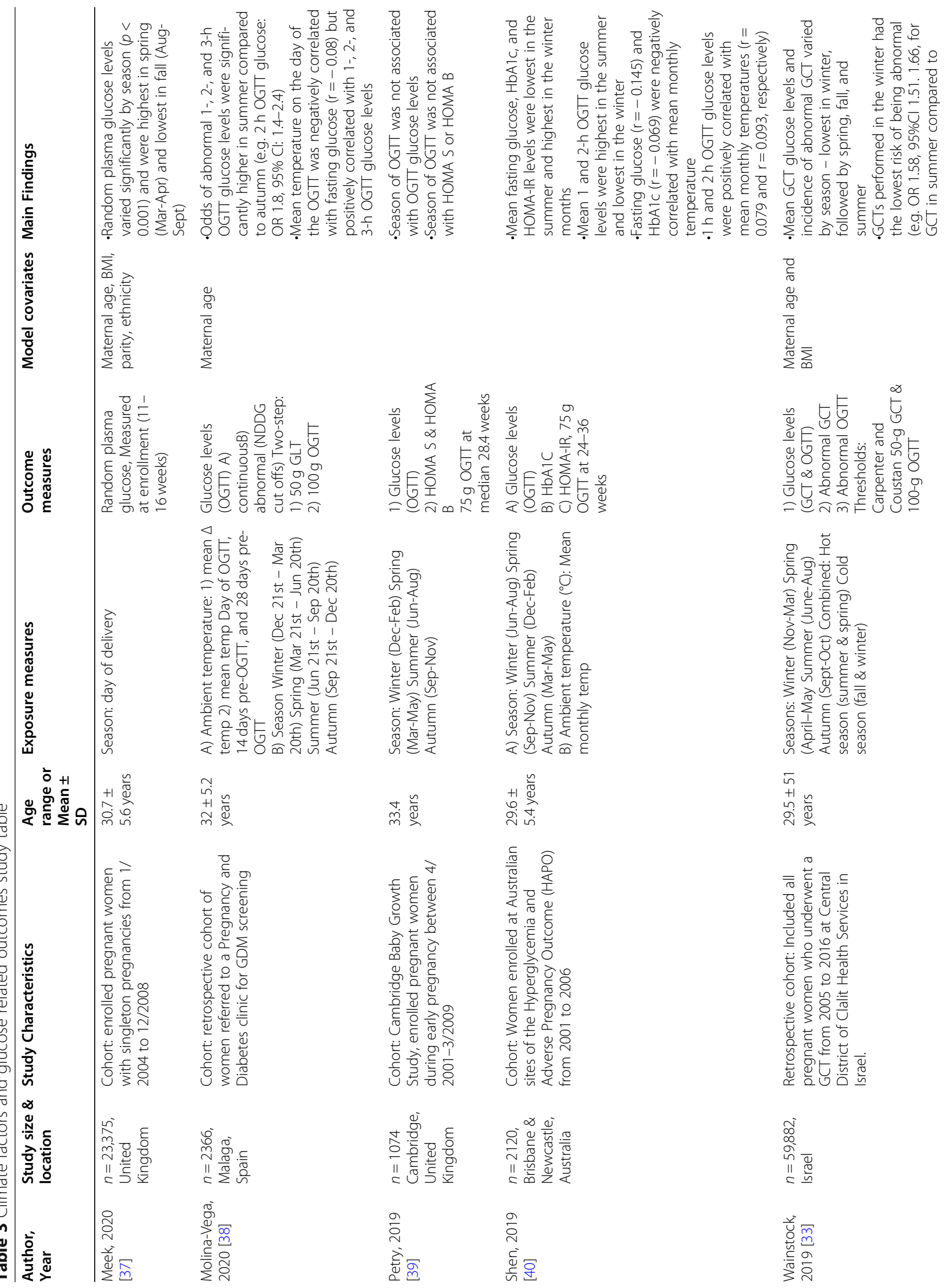




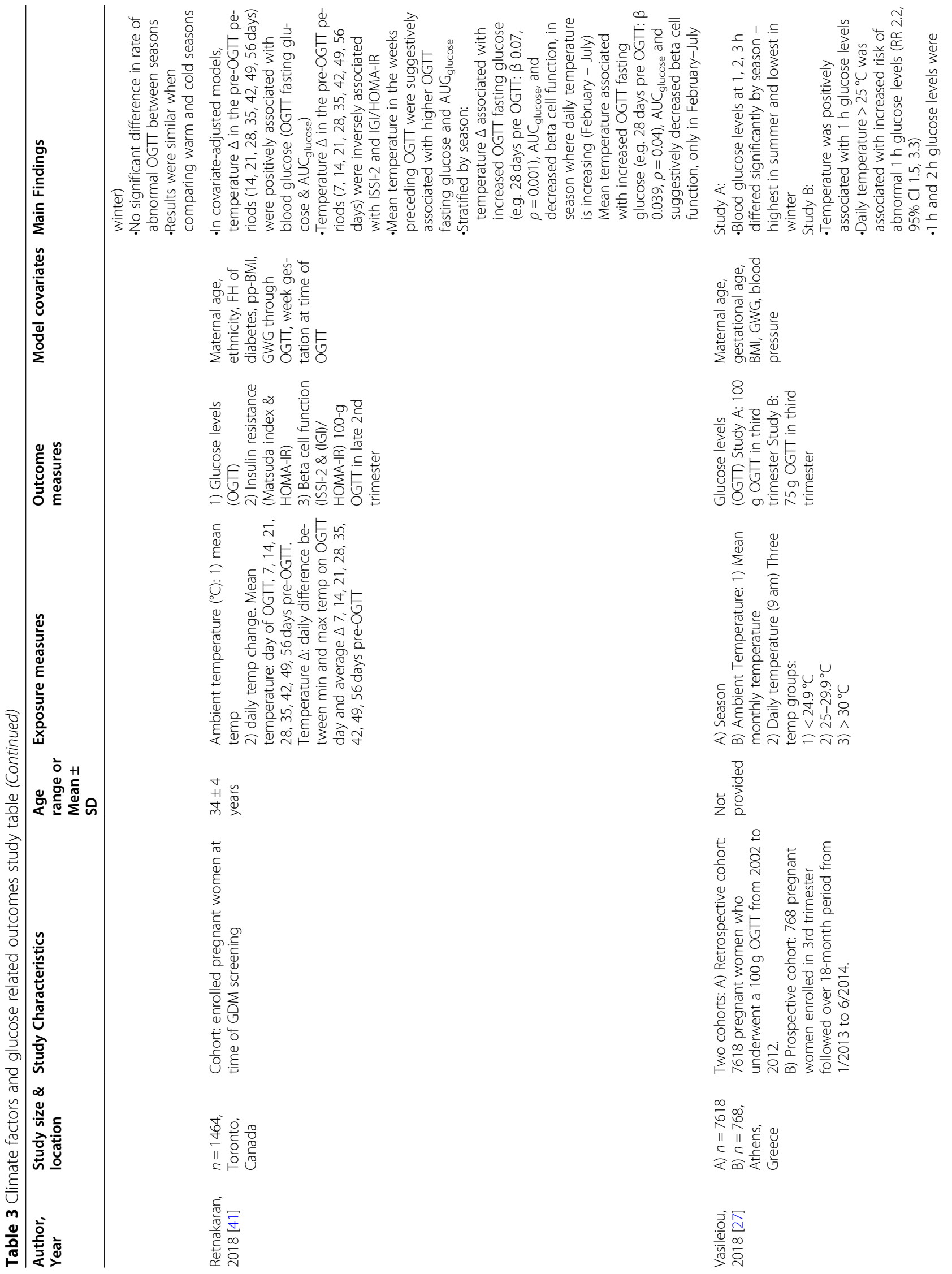




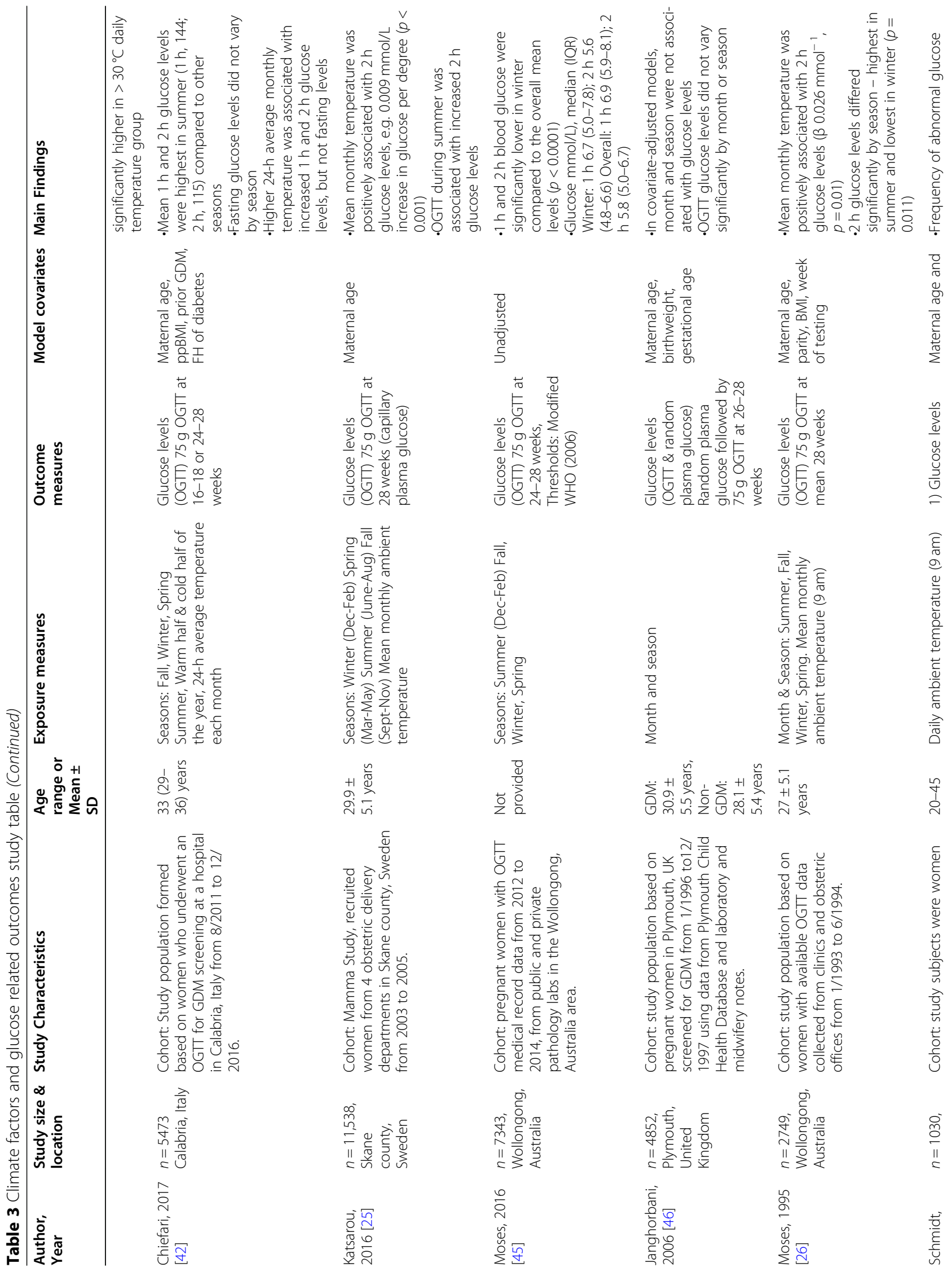




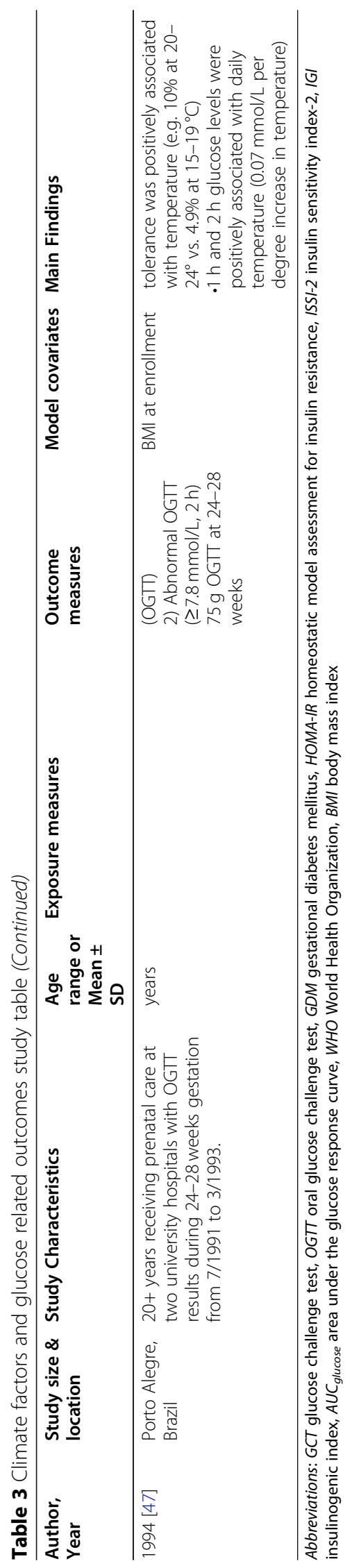


Three studies reported associations of mean temperature on the day of OGTT screening with increased odds or risk of GDM [21, 37, 38]. Mean temperature in the days and weeks leading up to the OGTT was also associated with increased odds or risk of GDM in some studies [21, 38, 43]. For example, a large Canadian registry-based cohort of 555,911 pregnancies from the greater Toronto area, higher ambient temperature averaged over the 30-days preceding routine GDM screening ( 27 weeks gestation) was significantly associated with higher odds of GDM [43]. Specifically, each 10-degree increase in mean 30-day temperature was associated with a $6 \%$ increased odds of GDM [43]. A separate smaller Toronto-based cohort study $(n=1464)$, found no association between mean ambient temperature and GDM when outdoor temperature was modeled as mean temperature in the weeks prior to GDM screening (i.e. 7, 14, 21, 28, 35, 42, 49, 56 days pre-screening) [41]. However, researchers did see associations between average daily change in ambient temperature (defined as the difference between the daily minimum and maximum temperatures) over the weeks pre-GDM screening and increased odds of GDM. For example, the odds of GDM were 1.20 (95\% CI $1.05,1.37)$ per degree increase in average daily change in ambient temperature $\left({ }^{\circ} \mathrm{C}\right)$ over the 14 days pre-GDM screening, with similar results over different time windows. These associations were only seen in the seasons where daily temperatures were increasing (February-July, i.e. SpringSummer) not in the seasons where daily temperatures were decreasing (August-January, i.e. Fall-Winter) [41]. Similarly, a Spanish cohort reported associations between higher mean temperatures on the day of the OGTT as well as 14- and 28-days pre-OGTT and increased risk of GDM (e.g. mean temp day of OGTT: OR 1.029, 95\% CI: 1.005-1.054), but in stratified analyses these associations were present only during seasons where daily temperatures were increasing [38], which may indicate the importance of other seasonal and physiological factors such as acclimatization, beyond ambient temperature alone.

Of note, all three of the studies reporting no association between temperature and GDM used 1-step screening approaches to diagnose GDM (Tables 1 \& 2 ), whereas the five studies that reported positive associations between temperature variables and GDM reported using a 2-step screening approach or were located in countries where a 2-step screening approach is most commonly used [55], although all women underwent both a GCT and $3 \mathrm{~h}$ OGTT as part of the study protocol in Retnakaran et al. [41] and both the IADPSG and Carpenter and Coustan criteria are used in Taiwan [21].
Ambient temperature \& glycemic outcomes Eight studies assessed associations of ambient temperature measures with maternal glycemic outcomes, including glucose levels as continuous outcomes, abnormal glucose screening results, insulin resistance, and beta cell function (Table 3) [25-27, 38, 40-42, 47]. Three cohorts, one in Greece $(n=768)$ [27], one in Brazil $(n=$ 1030) [47], and one in Spain $(n=2366)$ [38] found associations between higher ambient temperatures measured on the day of glucose screening (fasting 2-h 75-g OGTT [27, 47]; 3-h 100-g OGTT [38]) and higher $1 \mathrm{~h}$ and $2 \mathrm{~h}$ OGTT glucose levels. In four larger cohorts from Sweden $(n=11,538)$ [25], Italy $(n=5473)$ [42], and two from Australia $(n=2749$ [26], mean temperature of the calendar month of glucose testing (fasting 2-h 75-g OGTT) was positively associated with $2 \mathrm{~h}$ OGTT glucose levels, but only with $1 \mathrm{~h}$ OGTT glucose levels in two of the cohorts $[40,42]$.

In contrast, a recent Canadian study $(n=1464)$ only found suggestive covariate-adjusted associations of measures of mean temperature in the weeks prior to glucose testing (i.e. 7, 14, 21, 28, 35, 42, 49, 56 days prescreening) with higher glucose levels from a fasting 3-h 100-g OGTT [41]. However, they observed stronger and significant positive associations of mean daily temperature change in the weeks prior to glucose testing (defined as the difference between the daily minimum and maximum temperatures) with both OGTT fasting glucose levels and $\mathrm{AUC}_{\text {glucose }}$ (fasting, 30, 60, 120, and $180 \mathrm{~min}$ ) in covariate-adjusted models [41]. Increased mean daily temperature change in the weeks prior to glucose testing was also associated with decreased beta cell function based on measures of ISSI-2 and (IGI)/ HOMA-IR. When stratified by season, they found that these associations were only present in the season where daily temperatures were increasing (February - July, i.e. Spring-Summer) and not in the season where daily temperatures were decreasing (August - January, i.e. FallWinter) [41], indicating the potential importance of other seasonal factors, such as magnitude and direction of temperature fluctuations, rather than simple static temperature. Similar to results of the seasonality studies, the majority of the above studies found no association between temperature and fasting glucose levels, however two recent studies found inverse associations between temperature and fasting glucose levels [38, 40].

\section{Discussion}

In this systematic review, we summarized the current epidemiologic evidence evaluating climate factors and GDM. We found consistent evidence for an association of the summer season with GDM incidence or prevalence $[21,25,27,37,38,42,44-46]$ and $2 \mathrm{~h}$ glucose levels on the OGTT [25-27, 38, 40, 42, 45]. Evidence of 
an association between temperature and GDM was less consistent across studies. However, despite some heterogeneity in study findings, collective results suggest that higher ambient temperatures may be associated with higher glucose levels from GDM screening tests [25-27, $38,40,41,47]$ and higher odds or risk of GDM [21, 37, $38,41,43]$. Current study findings suggest that climate factors may be important to consider in the study and prevention of GDM, especially in the context of current and projected global climate change.

The consistent association of season with glycemic outcomes is supported by findings that season is associated with diabetes risk outside of pregnancy. Seasonal patterns have been observed for type 1 diabetes incidence [30]. However, unlike GDM incidence, which peaks in the summer, incidence of type 1 diabetes diagnosis generally peaks in the winter months. Type 1 diabetes and GDM have different pathophysiology, which may explain the discrepancy in seasonal patterns between diseases. Glycemic control among individuals with type 2 diabetes also varies by season in a similar pattern as with type 1 diabetes, with winter months showing higher hemoglobin A1c levels [56, 57]. Conversely, increased ambient temperature and heat stress have been consistently associated with increased risk of diabetes (type 1 and 2) and glucose intolerance in non-pregnant populations, supporting the association between temperature and increased glucose levels and GDM odds/risk during pregnancy [29]. For example, a large Spanish cohort of non-pregnant adults reported positive associations between higher mean annual ambient temperature and higher prevalence of prediabetes, diabetes, and insulin resistance, as well as higher fasting and 2-h glucose levels and HOMA-IR [58]. The fact that season is associated with the incidence of type 1 diabetes, glycemic control in type 2 diabetes, and GDM, coupled with the relatively consistent findings of effects of ambient temperature on diabetes odds/risk and glucose intolerance in pregnant and non-pregnant populations, suggest the need for future studies of seasonality and temperature related to diabetes risk, with a particular focus on the mechanisms and reasons for the discordant seasonal results across diabetes types.

The studies included in this review varied considerably in terms of exposure assessment, of GDM diagnostic criteria, glucose measurement, methodological approaches, and geographic location, which may explain some of the heterogeneity in study results. Results from the included studies on ambient temperature and GDM were inconsistent, which may partially be due to differences in GDM screening methods across studies (Table 1). Different diagnostic criteria across studies can affect estimated GDM prevalence, and could affect observed associations between climate factors and GDM. While the studies that found no association between ambient temperature and GDM all utilized 1-step diagnostic criteria with $2 \mathrm{~h} 75$-g OGTTs, the studies that reported associations between temperature variables and GDM reported using a 2-step diagnostic approach and/or were located in countries where a 2-step approach is generally used, although one study administered OGTTs to all women, and $3 \mathrm{~h} \mathrm{100-g} \mathrm{OGTTs} \mathrm{were} \mathrm{administered.} \mathrm{Dif-}$ ferences in glucose screening method (e.g. 75-g vs. 100-g OGTT) or timing of testing during pregnancy, could also contribute to the inconsistencies observed between associations of ambient temperature or season with different OGTT glucose levels. Some studies reported associations for certain OGTT glucose levels but not others (e.g. $2 \mathrm{~h}$ but not the $1 \mathrm{~h}$ values) $[25,26]$, while another study reported associations with the GCT glucose levels, but not with OGTT glucose levels [33]. Differences in ambient temperature patterns and ranges across geographic regions could also have contributed to inconsistencies in study findings. GDM prevalence is highly variable across geographic regions and is highest in the Middle East (median 15.2\%) and South-East Asia (15.0\%), regions with extreme high temperatures, and noticeably lower in Europe (6.1\%) and North America (7.0\%), regions with relatively lower temperatures [59]. However, no studies have investigated associations of absolute ambient temperatures and GDM across geographic regions.

Pregnant women may be more susceptible to the adverse health effects of climate related factors including heat and cold stress [60] and may therefore be particularly vulnerable to the development of diabetes and altered glycemic outcomes associated with climate factors in the face of increases in extreme temperatures.

Multiple hypotheses exist for the observed effect of ambient temperature and season on GDM and glycemic outcomes. One possible mechanism is through brown adipose tissue activation, which can induce weight changes and insulin sensitivity [29, 61, 62]. A recent study reported a positive association between ambient temperature and glycated hemoglobin (HbA1c) levels in 65,535 clinical patients [63]. The researchers hypothesized that these fluctuations could be due to seasonal alterations in brown adipose tissue (BAT) and its activation. BAT is sensitive to temperature fluctuations. At temperatures below the thermoneutral zone (i.e. 27$30{ }^{\circ} \mathrm{C}$ in unclothed adults), BAT is activated to produce heat [64], consuming large amounts of glucose from the blood in the process [65-68]. Glucose uptake during non-shivering thermogenesis in BAT occurs through upregulation of mitochondrial uncoupling protein 1 (UCP1) and glucose transporters (GLUT1 and GLUT4) $[63,69,70]$. Additionally, heat shock protein (HSP) expression in BAT is induced at cold temperatures [71- 
73]. Patients with diabetes and insulin resistance have reduced Hsp70 expression [74]. Reduced Hsp70 has been associated with hyperglycemia during pregnancy in mice [75].

In rodents, BAT may be especially important in regulating glucose metabolism during pregnancy; Qiao et al. showed that fetuses of UCP1 knockout dams had significantly higher blood glucose levels than wild-type dams [76]. At higher temperatures, there is a decrease in temperature-induced BAT activation, which could result in a decrease in glucose uptake. Separately, at higher temperatures beige and brown adipocytes can shift in chromatin structure to resemble white adipose tissue, leading to reduced expression of UPC1 and down regulation of lipid metabolism pathways [75]. In a clinical human population, BAT, detected using positron-emission tomographic and computed tomographic (PET-CT) scans, was inversely correlated with ambient temperature on the day of scan [77].

Alternative hypotheses to explain the positive association between ambient temperature and glucose levels include increased beta-cell dysfunction, insulin resistance, hemoconcentration and increased arterialization of venous blood $[5,33,78]$. One study in our review looked at associations between ambient temperature and markers of beta-cell function. The authors found that the higher mean daily temperature change in the 3-5 weeks prior to OGTT screening was significantly associated with decreased ISSI-2 and (IGI)/HOMA-IR, implicating beta-cell dysfunction as a potential pathophysiological mechanism behind the parallel associations with higher glucose levels and GDM prevalence, although suggestive associations were also seen with increase insulin resistance (i.e. Matsuda Index and HOMA-IR) [41]. In a large Spanish cohort of nonpregnant adults, higher annual mean temperature was associated with increased insulin resistance (HOMA-IR) [58]. Alternatively, higher ambient temperatures and increased activity in warmer weather could lead to dehydration, and resulting hemoconcentration, which could cause an apparent increase in blood glucose concentrations during glucose screening and resulting GDM diagnoses [33]. Similarly, blood flow distribution is altered at high temperatures, leading to increased arterialization of venous blood, which could result in higher glucose levels measured in venous blood samples leading to increases in failed GDM screening tests and GDM diagnoses. In climate chamber experiments, Moses et al. [5] and Dumke et al. [78] observed significantly increased levels of OGTT glucose levels $[5,78]$ and insulin levels [78] at higher temperatures in healthy male subjects. These physiological changes at high temperatures could cause transient elevations in measured blood glucose levels, leading to potential misclassification of abnormal glucose tolerance and GDM.

Seasonal factors unrelated to temperature may also contribute to the observed seasonal variation in GDM. Circadian and thermogenic networks in BAT are controlled by the nuclear receptor Rev-erba, which represses UPC1 expression in BAT $[79,80]$. Consequently, studies have shown that UCP1 expression in BAT follows a circadian rhythm in rodents, peaking during the day [63]. Seasonal changes in circadian rhythms, could contribute to the observed seasonal patterns of GDM risk. Alternatively, seasonal variations in physical activity and dietary patterns, as well as access to green space may also play a role in the observed seasonal variation in GDM and glycemic outcomes. Vitamin D may help regulate glucose homeostasis by increasing insulin sensitivity and beta-cell function, or decreasing systemic inflammation [35] and lower Vitamin D levels and Vitamin D deficiency, have been associated with increased GDM risk [81-85] and higher fasting glucose and insulin resistance during pregnancy [85]. Decreased sun exposure in winter months during early pregnancy could lead to decreased vitamin D levels during early pregnancy, which has been associated with subsequent risk of GDM during later pregnancy, at the time of routine GDM screening [82] In addition to increased GDM risk, lower Vitamin D levels during early pregnancy have been associated with higher HOMA-IR, lower Matsuda index, and lower ISSI-2 during in later pregnancy (2428 weeks) [82].

Temperature and season also affect other environmental factors known to be associated with GDM, such as air pollution [23, 24]. For example, exposure to ambient air pollutants, including nitrous oxides and $\mathrm{PM}_{2.5}$ (i.e. particulate matter with a diameter of $2.5 \mu \mathrm{m}$ or less), has been consistently associated with increased GDM risk [84, 86-91]. Additionally, potential seasonal changes in gut microbiome could contribute to the observed seasonal variation in glycemic outcomes [92, 93]; in GDM complicated pregnancies, altered maternal gut microbiome have been reported [94, 95]. Overall, the exact mechanism behind the effect of season and ambient temperature on GDM and glycemic outcomes remains unclear. Further research is needed to investigate the interplay between temperature and additional meteorological factors with glucose regulation in pregnancy using toxicologic and epidemiologic studies.

None of the identified studies assessed the associations of other meteorological-related factors such as precipitation and humidity on GDM risk. Seasonal variations in these factors could also contribute to the observed variation in GDM and glycemic outcomes. For example, a recent study found a positive correlation between diabetes incidence and precipitation in Cameroon [96]. 
Exposure to ambient air pollution has also been associated with increased risk of GDM [23] and varies by season and meteorological factors. However, further research is needed to understand the role of these additional factors and how they may be related to or interact with temperature to impact risk of GDM.

There is growing evidence that certain subsets of the population (i.e. those with a family history of diabetes or individuals who are overweight/obese) may be more susceptible to the effects of environmental exposures compared to others [97-100]. However, none of the reviewed studies assessed effect modification of the associations between climate factors and GDM or maternal glycemic outcomes by factors such as family history of diabetes, pre-pregnancy BMI, age, or race/ethnicity. Future studies should assess heterogeneity in associations across different population subgroups.

Due to the ubiquitous nature of environmental exposures, individuals are continuously exposed to complex combinations of environmental factors. While there is increasing awareness for the need to incorporate analyses of exposure mixtures and combinations in epidemiologic studies, none of the current studies have looked at cumulative effects of environmental exposures in the context of multiple climate-related factors such as temperature, humidity, and precipitation. Further research is needed to understand the potential cumulative and interactive effects of these climate factors on GDM risk.

Strategies for Evaluating Climate Factors in Future Studies of GDM:

1. Consider evaluating climate factors and accounting for lag time in modeling procedures.

2. Standardize GDM diagnostic criteria and screening methods.

3. Evaluate possible heterogeneous effects of climate factors across population subgroups by assessing effect modification to identify particularly vulnerable populations.

4. Consider the impact of climate factors on various populations based on region and space and the differential effects in given geographic areas.

5. Evaluate the potential confounding and/or modifying role of season of GDM diagnosis and ambient temperature prior to GDM screening in studies of pregnancy and neonatal outcomes in GDM complicated pregnancies.

6. Evaluate the cumulative impact of multiple climaterelated factors (e.g. temperature, season, humidity, precipitation, and the interplay with air pollution and other environmental factors) on GDM and related outcomes.

\section{Conclusion}

In summary, there is mounting evidence that exposure to certain climate factors-ambient temperature and season-during pregnancy is associated with increased risk of developing GDM and adverse glycemic outcomes. The seasonality of GDM was consistent across studies, with higher prevalence of GDM generally observed in the summer months. Furthermore, higher ambient temperature may be associated with elevated glucose levels from GDM screening tests. Associations between ambient temperature and GDM were more inconsistent; however, this could be due to differences in GDM diagnostic criteria. One major limitation of the current literature is the lack of consistency in both exposure and outcome assessment across studies; future studies should work to standardize these methods. Furthermore, future work should include more diverse study populations to allow researchers to identify potential high-risk population subgroups. Finally, future studies should include an emphasis on evaluating effects of exposure to multiple environmental and climate factors. Given the current GDM epidemic coupled with current and projected global climate change, understanding the extent to which climate factors might affect GDM risk is imperative to reducing the risk of this increasingly prevalent and costly pregnancy complication.

\section{Abbreviations \\ GDM: Gestational diabetes mellitus; BMI: Body mass index; PRISMA: Preferred reporting items for systematic reviews and meta-analyses; GCT: Glucose challenge test; OGTT: Oral glucose tolerance test; IADPSG: International Association of Diabetes in Pregnancy Study Group; IR: Insulin resistance; HOMA-IR: Homeostasis model assessment of insulin; ISSI-2: Insulin sensitivity index 2; |GI: Insulinogenic index; WHO: World Health Organization; ADIP S: Australian Diabetes in Pregnancy Society; NDDG: National Diabetes Data Group; FH: Family history; ppBMI: Pre-pregnancy body mass index; GWG: Gestational weight gain; LMP: Last menstrual period; AUC glucose: Area under the glucose response curve; PM2.5: Particulate matter with a diameter of $2.5 \mu \mathrm{m}$ or less; HbA1c: Glycated hemoglobin; BAT: Brown adipose tissue; UCP1: Mitochondrial uncoupling protein 1; GLUT: Glucose transporters; HSP: Heat shock protein; PET-CT: Positron-emission tomographic and computed tomographic}

\section{Authors' contributions}

$T J T, C E$, and FMB designed the systematic review. EVP. conducted the systematic search, data extraction, quality assessment of included studies, and wrote the manuscript. TJT, CE, and FMB provided quidance in synthesizing and interpreting the study results and all authors reviewed the manuscript for intellectual content and approved the final manuscript.

\section{Funding}

Author support for this systematic review was provided by the National Institute of Environmental Health Sciences of the National Institutes of Health, P30ES000002 and T32ES007069.

The content of this review is solely that of the authors and does not necessarily represent the official views of the National Institutes of Health.

\section{Competing interests}

The authors report no perceived or actual conflicts of interest.

\section{Author details}

${ }^{1}$ Department of Environmental Health, Harvard T.H. Chan School of Public Health, Building 1, Room 1411, 677 Huntington Ave, Boston, MA 02118, USA. 
${ }^{2}$ Medicine with specialization in Internal Medicine and General Medicine, Hochschule Fulda - University of Applied Sciences, Fulda, Germany. ${ }^{3}$ Adult Diabetes Section, Joslin Diabetes Center, Boston, MA, USA. ${ }^{4}$ Department of Epidemiology, Harvard T.H. Chan School of Public Health, Boston, MA, USA.

\section{Received: 10 June 2020 Accepted: 15 October 2020}

\section{Published online: 09 November 2020}

\section{References}

1. U.S. Global Change Research Program (USGCRP). The Impacts of Climate Change on Human Health in the United States: A Scientific Assessment. Washington, DC: U.S. Global Change Research Program; 2016.

2. Haines A, McMichael AJ, Epstein PR. Environment and health: 2. Global climate change and health. CMAJ. 2000;163(6):729-34.

3. National Academy of Sciences. The National Academies Collection: Reports funded by National Institutes of Health. Global Climate Change and Extreme Weather Events: Understanding the Contributions to Infectious Disease Emergence: Workshop Summary. Washington (DC): National Academies Press (US) National Academy of Sciences; 2008.

4. Phelps PB, National S, Technology C, Institute of M. In: Setlow V, Pope A editors. Conference on Human Health and Global Climate Change: Summary of the Proceedings. Washington (DC): National Academies Press (US); 1996

5. Moses RG, Patterson MJ, Regan JM, Chaunchaiyakul R, Taylor NA, Jenkins AB. A non-linear effect of ambient temperature on apparent glucose tolerance. Diabetes Res Clin Pract. 1997:36(1):35-40.

6. American Diabetes Association (ADA). Gestational diabetes mellitus. Diabetes Care. 2003;26(suppl 1):s103-s5.

7. International Diabetes Federation (IDF). IDF Diabetes Atlas, 8th edn. Brussels, Belgium. 2017

8. Behboudi-Gandevani S, Amiri M, Bidhendi Yarandi R, Ramezani TF. The impact of diagnostic criteria for gestational diabetes on its prevalence: a systematic review and meta-analysis. Diabetol Metab Syndrome. 2019;11:11.

9. Nicholas P, Deputy SYK, Elizabeth J, Conrey KMKB. Prevalence and Changes in Preexisting Diabetes and Gestational Diabetes Among Women Who Had a Live Birth — United States, 2012-2016; 2018.

10. DeSisto CL, Kim SY, Sharma AJ. Prevalence estimates of gestational diabetes mellitus in the United States, pregnancy risk assessment monitoring system (PRAMS), 2007-2010. Prev Chronic Dis. 2014;11:E104.

11. HAPO Study Cooperative Research Group (HSCR), Metzger BE, Lowe LP, Dyer AR, Trimble ER, Chaovarindr U, et al. Hyperglycemia and adverse pregnancy outcomes. N Engl J Med. 2008;358(19):1991-2002.

12. Bellamy L, Casas JP, Hingorani AD, Williams D. Type 2 diabetes mellitus after gestational diabetes: a systematic review and meta-analysis. Lancet (London, Engl). 2009;373(9677):1773-9.

13. Kim C, Newton KM, Knopp RH. Gestational diabetes and the incidence of type 2 diabetes: a systematic review. Diabetes Care. 2002;25(10):1862-8.

14. Lowe WL Jr, Scholtens DM, Lowe LP, Kuang A, Nodzenski M, Talbot O, et al. Association of Gestational Diabetes with Maternal Disorders of glucose metabolism and childhood adiposity. JAMA. 2018;320(10):1005-16.

15. Kramer CK, Campbell S, Retnakaran R. Gestational diabetes and the risk of cardiovascular disease in women: a systematic review and meta-analysis. Diabetologia. 2019;62(6):905-14.

16. Li J, Song C, Li C, Liu P, Sun Z, Yang X. Increased risk of cardiovascular disease in women with prior gestational diabetes: a systematic review and meta-analysis. Diabetes Res Clin Pract. 2018;140:324-38.

17. Lowe WL Jr, Scholtens DM, Kuang A, Linder B, Lawrence JM, Lebenthal Y, et al. Hyperglycemia and adverse pregnancy outcome follow-up study (HAPO FUS): maternal gestational diabetes mellitus and childhood glucose metabolism. Diabetes Care. 2019;42(3):372-80.

18. American College of Obstetricians and Gynecologists (ACOG). ACOG Practice Bulletin No. 190: gestational diabetes mellitus. Obstet Gynecol. 2018;131(2):e49-64.

19. Zhang C, Rawal S, Chong YS. Risk factors for gestational diabetes: is prevention possible? Diabetologia. 2016;59(7):1385-90.

20. Williams CB, labal S, Zawacki CM, Yu D, Brown MB, Herman WH. Effect of selective screening for gestational diabetes. Diabetes Care. 1999;22(3):41821.

21. Varshavsky J, Smith A, Wang A, Hom E, Izano M, Huang H, et al. Heightened Susceptibility: A Review of How Pregnancy and Chemical Exposures Influence Maternal Health. Reproductive toxicology (Elmsford, NY). 2019.
22. Ehrlich S, Lambers D, Baccarelli A, Khoury J, Macaluso M, Ho SM. Endocrine disruptors: a potential risk factor for gestational diabetes mellitus. Am J Perinatol. 2016;33(13):1313-8.

23. Elshahidi $\mathrm{MH}$. Outdoor air pollution and gestational diabetes mellitus: a systematic review and meta-analysis. Iran J Public Health. 2019;48(1):9.

24. Eze IC, Hemkens LG, Bucher HC, Hoffmann B, Schindler C, Kunzli N, et al. Association between ambient air pollution and diabetes mellitus in Europe and North America: systematic review and meta-analysis. Environ Health Perspect. 2015;123(5):381-9.

25. Katsarou A, Claesson R, Ignell C, Shaat N, Berntorp K. Seasonal pattern in the diagnosis of gestational diabetes mellitus in southern Sweden. J Diab Res. 2016;2016:8905474.

26. Moses R, Griffiths R. Is there a seasonal variation in the incidence of gestational diabetes? Diab Med. 1995;12(7):563-5.

27. Vasileiou V, Kyratzoglou E, Paschou SA, Kyprianou M, Anastasiou E. The impact of environmental temperature on the diagnosis of gestational diabetes mellitus. Eur J Endocrinol. 2018;178(3):209-14.

28. Intergovernmental Panel on Climate Change (IPCC). Climate Change 2014 Synthesis Report. Contribution of Working Groups I, II and III to the Fifth Assessment Report of the Intergovernmental Panel on Climate Change. Geneva: IPCC: 2014

29. Blauw LL, Aziz NA, Tannemaat MR, Blauw CA, de Craen AJ, Pijl H, et al. Diabetes incidence and glucose intolerance prevalence increase with higher outdoor temperature. BMJ Open Diabetes Res Care. 2017;5(1):e000317.

30. Moltchanova EV, Schreier N, Lammi N, Karvonen M. Seasonal variation of diagnosis of type 1 diabetes mellitus in children worldwide. Diab Med. 2009;26(7):673-8.

31. Tyrovolas S, Chalkias C, Morena M, Kalogeropoulos K, Tsakountakis N, Zeimbekis A, et al. High relative environmental humidity is associated with diabetes among elders living in Mediterranean islands. J Diab Metab Disord. 2014;13(1):25

32. Virtanen KA, Lidell ME, Orava J, Heglind M, Westergren $R$, Niemi $T$, et al. Functional brown adipose tissue in healthy adults. N Engl J Med. 2009; 360(15):1518-25.

33. Wainstock T, Yoles I. Pregnant women may be sweeter in the summer: seasonal changes in glucose challenge tests results. A population-based study. Diabetes Res Clin Pract. 2019;147:134-7.

34. Lucato P, Solmi M, Maggi S, Bertocco A, Bano G, Trevisan C, et al. Low vitamin $D$ levels increase the risk of type 2 diabetes in older adults: a systematic review and meta-analysis. Maturitas. 2017;100:8-15.

35. Alvarez JA, Ashraf A. Role of vitamin d in insulin secretion and insulin sensitivity for glucose homeostasis. Int J Endocrinol. 2010; 2010:351385

36. Moher D, Liberati A, Tetzlaff J, Altman DG. Preferred reporting items for systematic reviews and meta-analyses: the PRISMA statement. J Clin Epidemiol. 2009;62(10):1006-12.

37. Meek CL, Devoy B, Simmons D, Patient CJ, Aiken AR, Murphy HR, et al. Seasonal variations in incidence and maternal-fetal outcomes of gestational diabetes. Diabet Med. 2020;37(4):674-80.

38. Molina-Vega M, Gutiérrez-Repiso C, Muñoz-Garach A, Lima-Rubio F, Morcillo S, Tinahones FJ, et al. Relationship between environmental temperature and the diagnosis and treatment of gestational diabetes mellitus: an observational retrospective study. Sci Total Environ. 2020; 744.

39. Petry CJ, Fisher BG, Ong KK, Hughes IA, Acerini CL, Dunger DB. Temporal trends without seasonal effects on gestational diabetes incidence relate to reductions in indices of insulin secretion: the Cambridge baby growth study. Acta Diabetol. 2019;56(10):1133-40.

40. Shen EX, Moses RG, Oats JJN, Lowe J, Mclntyre HD. Seasonality, temperature and pregnancy oral glucose tolerance test results in Australia. BMC Pregnancy Child. 2019;19(1):263.

41. Retnakaran R, Ye C, Kramer CK, Hanley AJ, Connelly PW, Sermer M, et al. Impact of daily incremental change in environmental temperature on beta cell function and the risk of gestational diabetes in pregnant women. Diabetologia. 2018;61(12):2633-42.

42. Chiefari E, Pastore I, Puccio L, Caroleo P, Oliverio R, Vero A, et al. Impact of seasonality on gestational diabetes mellitus. Endocrine Metab immune Disord Drug Targets. 2017;17(3):246-52.

43. Booth GL, Luo J, Park AL, Feig DS, Moineddin R, Ray JG. Influence of environmental temperature on risk of gestational diabetes. CMAJ. 2017; 189(19):E682-e9. 
44. Verburg PE, Tucker G, Scheil W, Erwich JJ, Dekker GA, Roberts CT. Seasonality of gestational diabetes mellitus: a south Australian population study. BMJ Open Diabetes Res Care. 2016;4(1):e000286.

45. Moses RG, Wong VC, Lambert K, Morris GJ, San GF. Seasonal changes in the prevalence of gestational diabetes mellitus. Diabetes Care. 2016;39(7):121821.

46. Janghorbani M, Stenhouse E, Jones RB, Millward A. Gestational diabetes mellitus in Plymouth, U.K.: prevalence, seasonal variation and associated factors. J Reprod Med. 2006;51(2):128-34.

47. Schmidt MI, Matos MC, Branchtein L, Reichelt AJ, Mengue SS, lochida LC, et al. Variation in glucose tolerance with ambient temperature. Lancet (London, Engl). 1994;344(8929):1054-5.

48. Metzger BE, Gabbe SG, Persson B, Buchanan TA, Catalano PA, Damm P, et al. International association of diabetes and pregnancy study groups recommendations on the diagnosis and classification of hyperglycemia in pregnancy. Diabetes Care. 2010;33(3):676-82.

49. World Health Organization (WHO). Definition, Diagnosis and Classification of Diabetes Mellitus and its Complications. Report of a WHO Consultation. Part1: Diagnosis and Classification of Diabetes Mellitus. Geneva: World Health Organization; 1999.

50. World Health Organization (WHO). Definition and Diagnosis of Diabetes Mellitus and Intermediate Hyperglycaemia. Geneva: World Health Organization; 2006.

51. Martin Fl. The diagnosis of gestational diabetes. Ad Hoc Working Party. Med J Aust. 1991;155(2):112.

52. Carpenter MW, Coustan DR. Criteria for screening tests for gestational diabetes. Am J Obstet Gynecol. 1982;144(7):768-73.

53. National Diabetes Data Group (NDDG). Classification and diagnosis of diabetes mellitus and other categories of glucose intolerance. Diabetes. 1979;28(12):1039-57.

54. Su WL, Lu CL, Martini S, Hsu YH, Li CY. A population-based study on the prevalence of gestational diabetes mellitus in association with temperature in Taiwan. Sci Total Environ. 2020;714.

55. Diabetes Canada Clinical Practice Guidelines Expert Committee, Feig DS, Berger H, Donovan L, Godbout A, Kader T, et al. Diabetes Canada Clinical Practice Guidelines: Diabetes and Pregnancy. Can J Diab. 2018;42(Suppl 1): S255-S82.

56. Ishii H, Fau Suzuki H, Fau SH, Baba T, Fau BT, Nakamura K, Fau NK Watanabe T, Watanabe T. Seasonal variation of glycemic control in type 2 diabetic patients. 2001. p. 0149-5992. Print.

57. Gikas A, Sotiropoulos A, Pastromas V, Papazafiropoulou A, Apostolou O, Pappas S. Seasonal variation in fasting glucose and $\mathrm{HbA1c}$ in patients with type 2 diabetes. Prim Care Diab. 2009;3(2):111-4.

58. Valdés S, Doulatram-Gamgaram V, Lago A, García Torres F, Badía-Guillén R, Olveira $G$, et al. Ambient temperature and prevalence of diabetes and insulin resistance in the Spanish population: Di@bet.es study. Eur J Endocrinol. 2019:180(5):273-80.

59. McIntyre HD, Catalano P, Zhang C, Desoye G, Mathiesen ER, Damm P. Gestational diabetes mellitus. Nat Rev Dis Primers. 2019;5(1):47.

60. Balbus JM, Malina C. Identifying vulnerable subpopulations for climate change health effects in the United States. J Occup Environ Med. 2009:51(1): 33-7.

61. Hanssen MJ, Hoeks J, Brans B, van der Lans AA, Schaart G, van den Driessche JJ, et al. Short-term cold acclimation improves insulin sensitivity in patients with type 2 diabetes mellitus. Nat Med. 2015; 21(8):863-5.

62. Lowell BB, SS V, Hamann A, Lawitts JA, Himms-Hagen J, Boyer BB, et al. Development of obesity in transgenic mice after genetic ablation of brown adipose tissue. Nature. 1993;366(6457):740-2.

63. Lee P, Bova R, Schofield L, Bryant W, Dieckmann W, Slattery A, et al. Brown adipose tissue exhibits a glucose-responsive Thermogenic biorhythm in humans. Cell Metab. 2016;23(4):602-9.

64. Tews D, Wabitsch M. Braunes Fettgewebe: Energiebilanz und Thermoregulation. In: Hiort O, Danne T, Wabitsch M, editors. Pädiatrische Endokrinologie und Diabetologie. Berlin: Springer Berlin Heidelberg; 2018. p. $1-6$.

65. Ouellet V, Routhier-Labadie A, Bellemare W, Lakhal-Chaieb L, Turcotte E, Carpentier AC, et al. Outdoor temperature, age, sex, body mass index, and diabetic status determine the prevalence, mass, and glucose-uptake activity of 18F-FDG-detected BAT in humans. J Clin Endocrinol Metab. 2011;96(1): 192-9.
66. Saito M, Okamatsu-Ogura Y, Matsushita M, Watanabe K, Yoneshiro T, NioKobayashi J, et al. High incidence of metabolically active brown adipose tissue in healthy adult humans: effects of cold exposure and adiposity. Diabetes. 2009;58(7):1526-31.

67. Shao X, Shao X, Wang X, Wang Y. Characterization of brown adipose tissue (1)(8)F-FDG uptake in PET/CT imaging and its influencing factors in the Chinese population. Nucl Med Biol. 2016;43(1):7-11.

68. Hankir MK, Klingenspor M. Brown adipocyte glucose metabolism: a heated subject. EMBO Rep. 2018;19(9).

69. Symonds ME, Farhat G, Aldiss P, Pope M, Budge H. Brown adipose tissue and glucose homeostasis - the link between climate change and the global rise in obesity and diabetes. Adipocyte. 2019;8(1):46-50.

70. Olsen JM, Sato M, Dallner OS, Sandstrom AL, Pisani DF, Chambard JC, et al. Glucose uptake in brown fat cells is dependent on mTOR complex 2promoted GLUT1 translocation. J Cell Biol. 2014;207(3):365-74.

71. Matz JM, Blake MJ, Tatelman HM, Lavoi KP, Holbrook NJ. Characterization and regulation of cold-induced heat shock protein expression in mouse brown adipose tissue. Am J Phys. 1995;269(1 Pt 2):R38-47.

72. Matz JM, LaVoi KP, Epstein PN, Blake MJ. Thermoregulatory and heat-shock protein response deficits in cold-exposed diabetic mice. Am J Phys. 1996; 270(3 Pt 2):R525-32

73. Matz JM, LaVoi KP, Moen RJ, Blake MJ. Cold-induced heat shock protein expression in rat aorta and brown adipose tissue. Physiol Behav. 1996;60(5): 1369-74.

74. Kurucz I, Morva A, Vaag A, Eriksson KF, Huang X, Groop L, et al. Decreased expression of heat shock protein 72 in skeletal muscle of patients with type 2 diabetes correlates with insulin resistance. Diabetes. 2002;51(4):1102-9.

75. Xing B, Wang L, Li Q, Cao Y, Dong X, Liang J, et al. Hsp70 plays an important role in high-fat diet induced gestational hyperglycemia in mice. $J$ Physiol Biochem. 2015;71(4):649-58.

76. Qiao L, Lee S, Nguyen A, Hay WW Jr, Shao J. Regulatory effects of brown adipose tissue thermogenesis on maternal metabolic adaptation, placental efficiency, and fetal growth in mice. Am J Physiol Endocrinol Metab. 2018; 315(6):E1224-e31.

77. Cypess AM, Lehman S, Williams G, Tal I, Rodman D, Goldfine AB, et al. Identification and importance of brown adipose tissue in adult humans. N Engl J Med. 2009;360(15):1509-17.

78. Dumke CL, Slivka DR, Cuddy JS, Hailes WS, Rose SM, Ruby BC. The effect of environmental temperature on glucose and insulin after an Oral glucose tolerance test in healthy young men. Wilderness Environ Med. 2015;26(3): $335-42$.

79. Everett LU, Lazar MA. Nuclear receptor rev-erbalpha: up, down, and all around. Trends Endocrinol Metab. 2014;25(11):586-92.

80. Gerhart-Hines Z, Feng D, Emmett MJ, Everett L, Loro E, Briggs ER, et al. The nuclear receptor rev-erbalpha controls circadian thermogenic plasticity. Nature. 2013;503(7476):410-3.

81. Al-Ajlan A, Al-Musharaf S, Fouda MA, Krishnaswamy S, Wani K, Aljohani $N J$, et al. Lower vitamin D levels in Saudi pregnant women are associated with higher risk of developing GDM. BMC Pregnancy Child. 2018;18(1):86

82. Lacroix M, Battista MC, Doyon M, Houde G, Ménard J, Ardilouze JL, et al. Lower vitamin $D$ levels at first trimester are associated with higher risk of developing gestational diabetes mellitus. Acta Diabetol. 2014;51(4):609-16.

83. Poel YH, Hummel P, Lips P, Stam F, van der Ploeg T, Simsek S. Vitamin D and gestational diabetes: a systematic review and meta-analysis. Eur J Intern Med. 2012;23(5):465-9.

84. Zhang MX, Pan GT, Guo JF, Li BY, Qin LQ, Zhang ZL. Vitamin D deficiency increases the risk of gestational diabetes mellitus: a meta-analysis of observational studies. Nutrients. 2015;7(10):8366-75.

85. Zhang Y, Gong Y, Xue H, Xiong J, Cheng G. Vitamin D and gestational diabetes mellitus: a systematic review based on data free of Hawthorne effect. BJOG. 2018;125(7):784-93.

86. Pedersen M, Olsen SF, Halldorsson TI, Zhang C, Hjortebjerg D, Ketzel M, et al. Gestational diabetes mellitus and exposure to ambient air pollution and road traffic noise: a cohort study. Environ Int. 2017;108:253-60.

87. Pan SC, Huang CC, Lin SJ, Chen BY, Chan CC, Leon Guo YL. Gestational diabetes mellitus was related to ambient air pollutant nitric oxide during early gestation. Environ Res. 2017;158:318-23.

88. Robledo CA, Mendola P, Yeung E, Mannisto T, Sundaram R, Liu D, et al. Preconception and early pregnancy air pollution exposures and risk of gestational diabetes mellitus. Environ Res. 2015;137:316-22. 
89. Malmqvist E, Jakobsson K, Tinnerberg H, Rignell-Hydbom A, Rylander L. Gestational diabetes and preeclampsia in association with air pollution at levels below current air quality guidelines. Environ Health Perspect. 2013; 121(4):488-93.

90. Choe SA, Kauderer S, Eliot MN, Glazer KB, Kingsley SL, Carlson L, et al. Air pollution, land use, and complications of pregnancy. Sci Total Environ. 2018; 645:1057-64.

91. Shen HN, Hua SY, Chiu CT, Li CY. Maternal Exposure to Air Pollutants and Risk of Gestational Diabetes Mellitus in Taiwan. Int J Environ Res Public Health. 2017;14(12).

92. Smits SA, Leach J, Sonnenburg ED, Gonzalez CG, Lichtman JS, Reid G, et al. Seasonal cycling in the gut microbiome of the Hadza hunter-gatherers of Tanzania. Science (New York, NY). 2017;357(6353):802-6.

93. Hisada T, Endoh K, Kuriki K. Inter- and intra-individual variations in seasonal and daily stabilities of the human gut microbiota in Japanese. Arch Microbiol. 2015;197(7):919-34.

94. Ponzo V, Fedele D, Goitre I, Leone F, Lezo A, Monzeglio C, et al. Diet-Gut Microbiota Interactions and Gestational Diabetes Mellitus (GDM). Nutrients. 2019;11(2).

95. Kuang YS, Lu JH, Li SH, Li JH, Yuan MY, He JR, et al. Connections between the human gut microbiome and gestational diabetes mellitus. GigaScience. 2017:6(8):1-12.

96. Lontchi-Yimagou E, Tsalefac M, Tapinmene LM, Noubiap JJ, Balti EV, Nguewa JL, et al. Seasonality in diabetes in Yaounde. Cameroon. 2016;16: 470.

97. Rahman ML, Zhang C, Smarr MM, Lee S, Honda M, Kannan K, et al. Persistent organic pollutants and gestational diabetes: a multi-center prospective cohort study of healthy US women. Environ Int. 2019;124:24958.

98. Williams AD, Grantz KL, Zhang C, Nobles C, Sherman S, Mendola P. Ambient volatile organic compounds and racial/ethnic disparities in gestational diabetes mellitus: are Asian/Pacific islander women at greater risk? Am J Epidemiol. 2019;188(2):389-97.

99. Jensen RC, Glintborg D, Timmermann CAG, Nielsen F, Kyhl HB, Andersen $H R$, et al. Perfluoroalkyl substances and glycemic status in pregnant Danish women: the Odense child cohort. Environ Int. 2018;116:101-7.

100. Xia X, Liang C, Sheng J, Yan S, Huang K, Li Z, et al. Association between serum arsenic levels and gestational diabetes mellitus: A population-based birth cohort study. Environ Poll (Barking, Essex : 1987). 2018;235:850-6.

\section{Publisher's Note}

Springer Nature remains neutral with regard to jurisdictional claims in published maps and institutional affiliations.

Ready to submit your research? Choose BMC and benefit from:

- fast, convenient online submission

- thorough peer review by experienced researchers in your field

- rapid publication on acceptance

- support for research data, including large and complex data types

- gold Open Access which fosters wider collaboration and increased citations

- maximum visibility for your research: over $100 \mathrm{M}$ website views per year

At BMC, research is always in progress.

Learn more biomedcentral.com/submissions 